\title{
The Effect of VDT Work on the Fluctuations of Accommodation
}

\author{
Masako TANAHASHI, Masaru MIYAO, Hisataka SAKAKIBARA, \\ Taka'aki KONDO, Yasuhiro AKAMATSU, Kuniko TAKIHI, \\ Tomoko YAMAUCHI, Katsumi YAMANAKA, \\ Shin'ya YAMADA and Seishi TOMIYASU*
}

\author{
Department of Public Health, Nagoya University School of \\ Medicine, Showa-ku, Nagoya 466, Japan \\ *Department of Ophthalmology, Nagoya University School of \\ Medicine, Showa-ku, Nagoya 466, Japan
}

(Received March 14, 1986 and in revised form June 13, 1986)

\begin{abstract}
Fluctuations in accommodation, accommodative function, visual acuity and subjective symptom were investigated on the basis of two hours of character search work by VDT operators. As a means to determine the visual load encountered in VDT work, the fluctuations in accommodation were analyzed using the computer method developed by the authors in eight young women. Visual acuity and amplitude of accommodation in the dominant eye diminished with VDT work time. In terms of the fluctuations in accommodation, it was found that, as VDT work time progressed, the frequency of the peak frequency band range lowered and the low-frequency ratio increased. Compared to the pre-test level, there was a significant increase in the low-frequency ratio after 2 hours of VDT work. With time, the mean number of complaints of eye strain and fatigue increased significantly in VDT work. The low-frequency ratio of fluctuation in accommodation was showed to increase before the number of complaints were found to increase. Results suggested that computer analysis using the scale method offers a faster, more objective approach to measure visual load from VDT work.
\end{abstract}

Key words : Fluctuations of accommodation-Frequency analysis-Infrared optometer-Scale method-Subjective symptoms-Visual load-Eyedness-VDT

\section{INTRODUCTION}

The use of computer became widespread in the sixties. With the computers of the time, data inputs were obtained by cards punched with holes by keypunchers, and operators produced the results of calculations by printer outputs. With the sophistication of computer technology, however, a cathode ray tube (CRT) was used to display the results, making it possible to key in data inputs with a keyboard while watching the display. This meant a considerable change 
in the relationship between the operator and the computer. The visual display terminal (VDT), Man-Machine System of operation was born. ${ }^{1)}$ And in Japan, VDT work saw a sharp upturn around 1978.

During this initial stage of upgraded computerization, operators began to encounter health difficulties in the form of tenosynovitis and occupational cervicobrachial disorders (OCD). ${ }^{2)}$ As VDT work became more commonplace, reports were made of operator visual fatigue, ${ }^{3,4)}$ neck-shoulder-arm disorders, ${ }^{5,6)}$ psychosomatic diseases, ${ }^{7)}$ pregnancy hazards ${ }^{8)}$ and facial dermatitis. ${ }^{9)}$ The most frequent complaint voiced by operators engaged in VDT work was of visual fatigue. ${ }^{10,11)}$

In the present experimental study, the effect of VDT work on the fluctuations of accommodation ${ }^{12,13)}$ was investigated. The conventional analysis of the fluctuations in accommodation relied upon the inspection method, so reproducibility and objectivity were compromised. To avoid such drawbacks, Miyao et al. ${ }^{14)}$ developed a scale methed of computer analysis to analyze the wave forms in fluctuating accommodation. The present study is an attempt to employ this computer method for analysis of fluctuating accommodation in order to assess the effects of VDT work on visual function.

In 1983 the Japanese Ministry of Labor conducted a sample survey ${ }^{15)}$ on the basis of which it was estimated that about $33 \%$ of all VDT operators were young women between the ages of 20 and 29 years. Thus, young women represent a relatively high proportion of VDT workers. VDT test in which Japanese characters were the object of a search task was devised to examine such young women affected by VDT work. The search task required focusing one's attention on the CRT display from the beginning to the end, and was a machine-paced task which made it impossible for operator to keep one's pace.

The present investigation sought to determine how VDT work changed the fluctuations of accommodation, and how this fluctuation related to other visual functions and subjective complaints.

\section{Materials AND Methods}

\section{Test subjects and experimental conditions}

The subjects were eight healthy 18 -year-old female volunteers who neither wore glasses nor contact lenses in everyday life. Two of them wore glasses for VDT work. All subjects had normal corrected acuity of over 1.0, and no one was found to suffer from any ophthalmological disease.

The tests were conducted from February 15 to 25 in 1985 in our University research laboratory. The temperature in the laboratory ranged from $22^{\circ} \mathrm{C}$ to $26^{\circ} \mathrm{C}$ (air-conditioned), and humidity was maintained between 40 percent to 50 percent. The CRT employed was an NEC Model PCKD-551 color display (dark background) with a 14-inch screen. Characters were $16 \times 16$ dot types in green, while alphanumerics were $7 \times 13$ dot types. CRT ambient illuminance 
was 410-430 lux.

\section{Experimental method}

\section{2-1. VDT work load}

Japanese character search testing was conducted on subjects for 2 hours in the morning. The procedure was as follows. Some 228 Japanese characters (arranged in rows of 19 across and 12 down) which were randomly sampled from among 2934 characters (JIS 1 Standard excluding symbols, alphanumerics, hiragana and katakana), were displayed on the CRT. These were called the standard display characters. The subjects were asked to delete any characters appearing which contained the [i] vowel sound (e.g., ki, shi, mi, etc.). These were termed the target characters. However, the cursor was arranged to move from one character to another at the rate of one per $0.75 \mathrm{sec}$. The subject was instructed to judge whether or not the character was indeed a target character; if so, she was to delete it from the display using the space key on the keyboard.

To prevent any reduction in execution, subjects were subjected to a warning sound each time they mistakenly erased a wrong character. When a given screen of characters had been completed, the next screen would appear automatically, so that the operator had to continue the search. The time to check a specific display screen was $2 \mathrm{~min}$. and $51 \mathrm{sec}$. Subjects worked with 21 display screens the first hour, and 42 over the entire 2-hour test period.

The subject was free to assume any posture in her stiff-backed office chair. The illuminance of the display screen was adiustable to individual preferences. Screen-eye distance was $40-60 \mathrm{~cm}$.

\section{2-2. Measurement of visual function}

Visual function was measured 3 times; before, 1 and 2 hours after VDT work. Items measured were: visual acuity, accommodative function and fluctuating accommodation.

Visual acuity was tested with a Landolt's ring chart positioned $5 \mathrm{~m}$ away. Accommodative function was checked for near and far point distaince by accommodo polyrecorder (Kowa HS-9D). Fluctuation in accommodation was tested with an infrared optometer (Kowa Optron-2), by making the subject focus at a target point 1 diopter from the far point, during which time the wave form of the fluctuating accommodation was registered by a data recorder (TEAC R-70 A). These data were then automatically analyzed in a personal computer (NEC model PC9801) using the scale method. To prevent subject movement at the time of fluctuating accommodation measurement, the subject's head was strapped stationary by means of a band. When the fluctuating accommodation was measured, the room was darkened to enable adequate pupil enlargement.

\section{2-3. Subjective complaints}

The subjective symptoms were shown in Table 1 . The first group of these items consisted of the 23 headings for such complaints according to Suzumura. ${ }^{16)}$ 
Table 1. Checklist of subjective symptoms

\begin{tabular}{|c|c|}
\hline Eye strain & 4. Yawning a lot \\
\hline 1. Eyelids feel heavy & 5. Head feels hot or muddled \\
\hline 2. Feel pressure in eyes & 6. Feel drowsy \\
\hline 3. Difficult to keep eyes open & 7. Eye strain \\
\hline $\begin{array}{l}\text { 4. Feel relieved when eyelids are } \\
\text { lightly pressed }\end{array}$ & $\begin{array}{l}\text { 8. Rigid or clumsy movements } \\
\text { 9. Feel unsteady while standing }\end{array}$ \\
\hline 5. Pain in the deepest part of eyes & 10. Want to lie down \\
\hline 6. Flickering sensation & \\
\hline 7. Blurred vision & Difficulty in concentration \\
\hline 8. Out of focus & 11. Find difficulty in thinking \\
\hline 9. Dazzling sensation & 12. Become weary while talking \\
\hline 10. Cloudy vision despite effort to focus & 13. Become nervous \\
\hline 11. Eyes easily fill with tears & 14. Unable to concentrate attention \\
\hline 12. Throbbing eye pain & 15. Have no interest in thinking \\
\hline 13. Red eyes & 16. Apt to forget things \\
\hline 14. See light flashes with eyes closed & 17. Lack of self-confidence \\
\hline 15. Increased discharge from eyes & 18. Anxious about things \\
\hline $\begin{array}{l}\text { 16. Inabitity to distinguish colors as } \\
\text { usual }\end{array}$ & $\begin{array}{l}\text { 19. Unable to straighten up } \\
\text { 20. Lack patience }\end{array}$ \\
\hline 17. Afterimage remains & Sense of something physically wrong \\
\hline 18. White walls have a different color & 21. Have a headache \\
\hline $\begin{array}{l}\text { 19. Color remains in eyes } \\
\text { 20. Double vision }\end{array}$ & $\begin{array}{l}\text { 22. Feeling of stiffness in the neck or } \\
\text { the shoulders }\end{array}$ \\
\hline 21. Eyes feel hot & 23. Feel a pain in the low back \\
\hline 22. Eyes feel dry & 24. Feel constrained in breathing \\
\hline 23. Eyes feel itchy & 25. Feel thirsty \\
\hline Fatigue symptoms & 26. Husky voice \\
\hline Dullness and sleepiness & 27. Dizziness \\
\hline 1. Head feels heavy & 28. Eyelid spasms \\
\hline 2. Whole body feels tired & 29. Tremor in the limbs \\
\hline 3. Legs feel tired & 30. Feel ill \\
\hline
\end{tabular}

These were called symptoms of eye strain. Also employed were the 30 subjective fatigue complaints, ${ }^{17}$ ) the second group of items, put forth by the Industrial Fatigue Research Committee of the Japan Association of Industrial Health (10 items involving dullness and sleepiness, 10 concerning the difficulty of concentration, and 10 with a sense of something physically wrong). These were termed the work fatigue complaints. Subjective complaints were examined just before, and at one and two hours following VDT work. Questions posed were replied to by number (1: Hardly feel it, 2: Feel it, 3: Feel it strongly), and appeared in sequence on the display. The replies to 2 or 3 were treated as complaints. This subjective symptom survey and the search test itself were administered automatically from the computer programmed routine.

The test was conducted according to the following procedure.

9:00 am : Meeting with subjects, orientation

$9: 30 \quad:$ Pre-test measurement 


$\begin{aligned} & \text { Pre-test subjective symptom survey } \\ & 9: 50-10: 50: \text { Character search test by VDT } \\ & 10: 50: \text { Subjective symptom survey } 1 \mathrm{hr} \text { after test } \\ & \text { Measurement } 1 \mathrm{hr} \text { after test } \\ & 11: 10-12: 10: \text { Character search test by VDT } \\ & \text { Subjective symptom survey } 2 \mathrm{hr} \text { after test } \\ & \text { Measurement } 2 \mathrm{hr} \text { after test } \\ & 12: 30 \quad: \text { Conclusion }\end{aligned}$

Subjects were allowed to practice the character search task for an hour on the day before the actual testing. This gave an opportunity to practice measurements of visual function. Subjects were instructed to get more than 8 hours of sleep the night before the test was conducted, not to tire their eyes unduly on the test day itself, and to have breakfast.

\section{Analytical procedures}

\section{3-1 Fluctuations in accommodation}

Using an infrared optometer, subject accommodative fluctuation was measured by making the subject focus for $20 \mathrm{sec}$ at a target which was placed 1D inside of the far point. At this time, the data were recorded (wave form in fluctuating accommodation) and automatically analyzed by the scale method by means of a personal computer. Wave forms were divided into 9 different frequency bands: $0.50-0.63 \mathrm{~Hz}, 0.63-0.80 \mathrm{~Hz}, 0.80-1.00 \mathrm{~Hz}, 1.00-1.25 \mathrm{~Hz}, 1.25-1.60 \mathrm{~Hz}, 1.60-$ $2.00 \mathrm{~Hz}, 2.00-2.50 \mathrm{~Hz}, 2.50-3.15 \mathrm{~Hz}$ and $3.15-4.00 \mathrm{~Hz}$. In each frequency band range, the time for the wave form to appear was totaled, and the ratio of measure-time was calculated. This was called the percent time ( $\%$ time). The $0.50-4.0 \mathrm{~Hz}$ range was analyzed in terms of fluctuating accommodation, and the $0.5-1.0 \mathrm{~Hz}$ range was taken to be the low-frequency range. The percent time of this low-frequency range was obtained in relation to the overall percent time of fluctuating accommodation. This was termed the low-frequency ratio. ${ }^{18)}$

3-2. Amount of information transmitted

In the present experiment, the number of characters displayed and the cursor speed were kept constant. Hence, the performance of the task was in terms of the subject's correctness of judgment. Mistakes could be grouped into two: failure to delete the target character, or deletion of other than the target character. The amount of information transmitted was calculated according to Shannon's mathematical theory of communication. ${ }^{19)}$ The ratio of the amount of information transmitted to amount of information displayed was obtained, and this was named the information transmission ratio by the present authors. Work accuracy was expressed in terms of this information transmission ratio in the present study. 


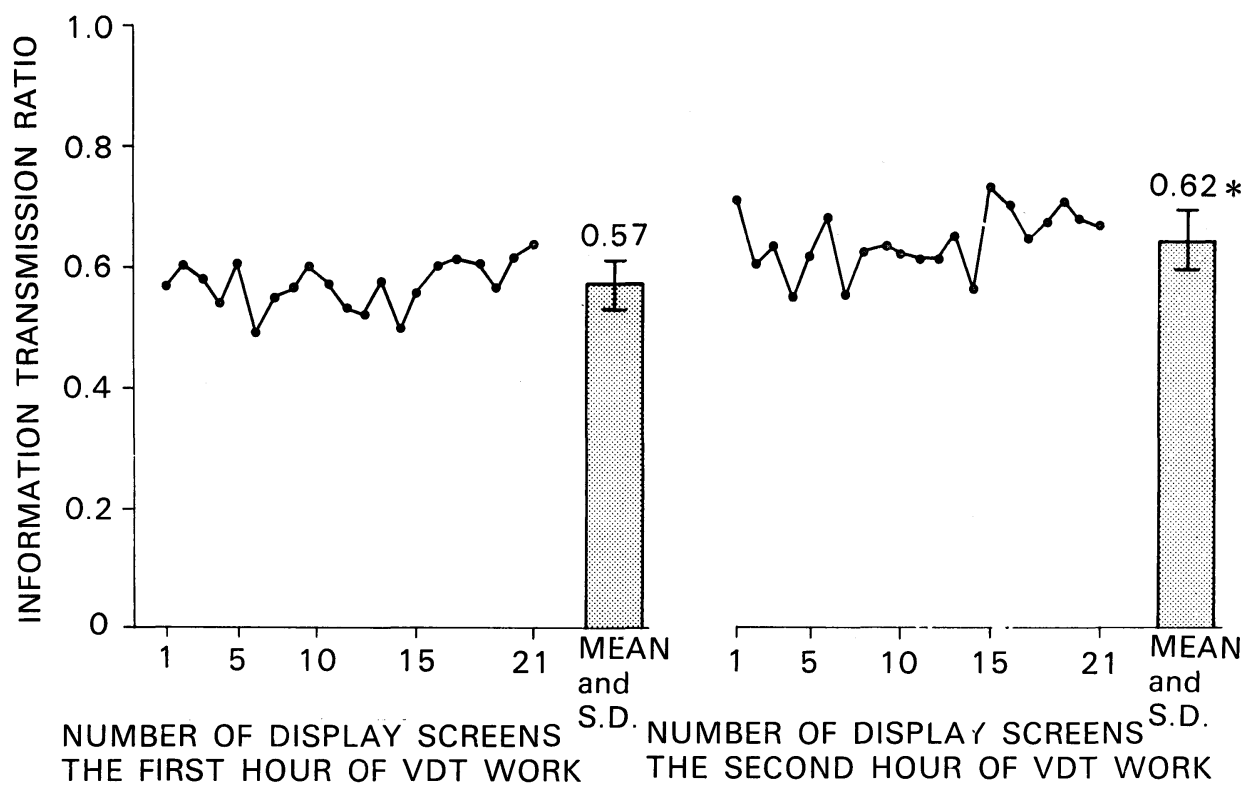

Fig. 1. Changes in information transmission ratio of characters displayed.

Plotted value represents means for eight subjects.

*: Significantly different from the first hour of VDT work (t-test).

Calculation of information transmission ratio

Amount of information transmitted

$$
H_{T}=\log _{2} 228+\frac{1}{228} \sum\left\{A_{i j} \log _{2} \frac{A_{i j}}{A_{i .} A_{. j}}\right\}
$$

Amount of information displayed

$$
H_{S}=\log _{2} 228-\frac{1}{228} \Sigma\left(A_{i} . \log _{2} A_{i} .\right)
$$

Information transmission ratio

\begin{tabular}{cllll}
$H=\frac{H_{T}}{H_{S}}$ & & & & \\
& & \multicolumn{4}{c}{ Display characters } \\
\cline { 3 - 5 } & & $\mathrm{T}$ & $\mathrm{N}$ & Sum \\
\hline Judgement of subjects & $\mathrm{D}$ & $\mathrm{A}_{11}$ & $\mathrm{~A}_{12}$ & $\mathrm{~A}_{1}$ \\
& $\mathrm{R}$ & $\mathrm{A}_{21}$ & $\mathrm{~A}_{22}$ & $\mathrm{~A}_{2}$. \\
& Sum & $\mathrm{A}_{1}$ & $\mathrm{~A} .2$ & 228
\end{tabular}

$\mathrm{T}=$ Target characters

$\mathrm{N}=$ Non-target characters

$\mathbf{D}=$ Deleted characters

$\mathbf{R}=$ Residual characters

$A_{i j}=$ Number of chracters within each item 


\section{RESUlts}

1. Effects of VDT work time

1-1. Work accuracy

VDT work performance could be expressed in terms of the correctness of the subject's judgment in this study. Figure 1 presents the changes in the information transmission ratio for each set of characters displayed. This ratio was an average of 0.57 for the first hour of VDT work, against 0.62 for the second hour of same. This reflects a significant difference: the information transmission ratio was much higher in the second hour than in the first $(P<0.05$, t-test).

1-2. Visual acuity and accommodative function

Visual acuity and accommodative function were analyzed separately for the dominant and non-dominant eye, using the hole test ${ }^{20}$ for ocular dominance. Dominant eye laterality was found in 4 right eyes and 4 left eyes in 8 subjects. Ability to see with the dominant eye was calculated to obtain a mean value by logarithmic translation. As evident from Fig. 2, the value was 0.97 before work,

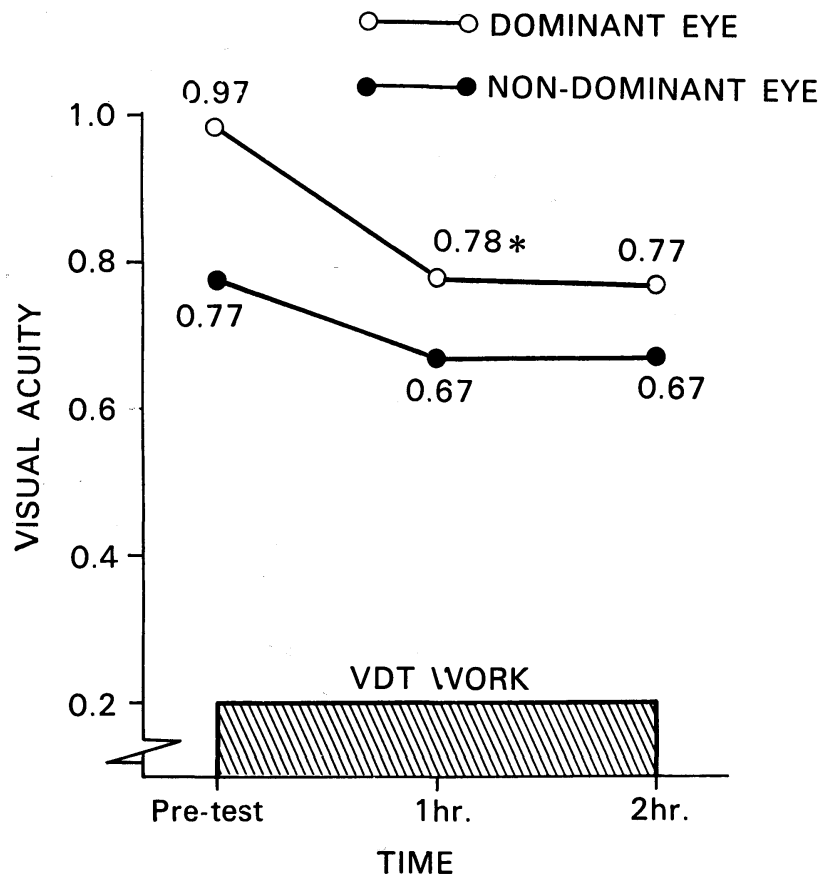

Fig. 2. Changes in visual acuity with VDT work.

Plotted value represents means of logarithm for eight subjects.

*: Significantly different from the pre-test level.

$(\mathrm{p}<0.05$, Wilcoxon matched-pairs signed-rank test) 


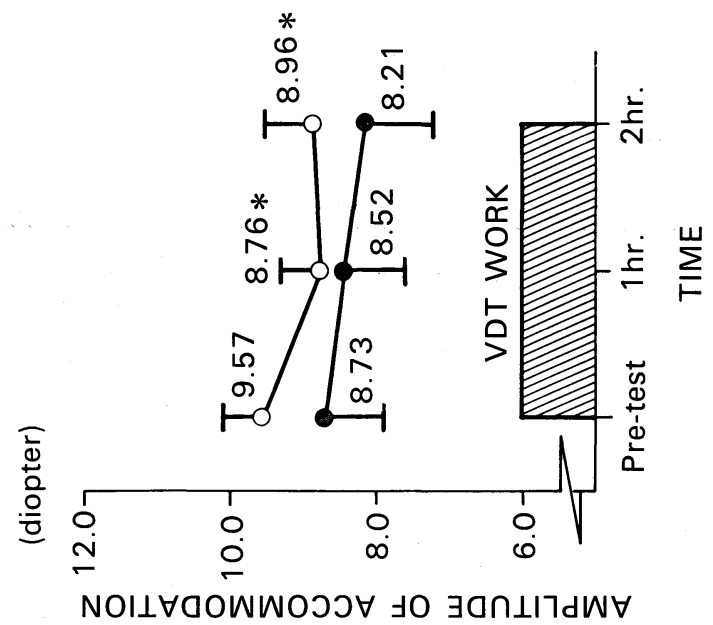

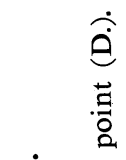
宽若

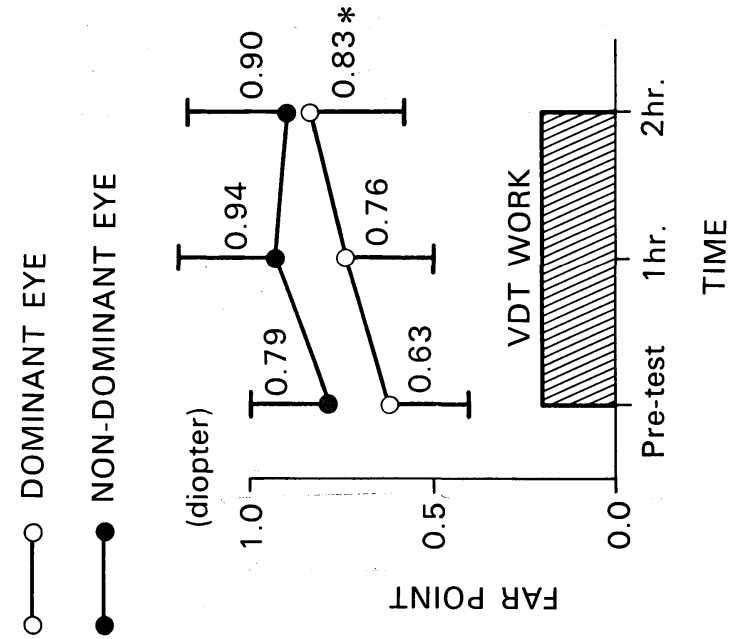

官官

逭

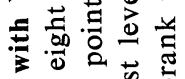

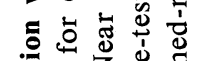

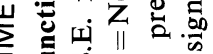
$\Xi$ is 跣 ฮี . 묘

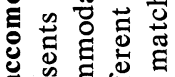
纯 $\Xi$ 家

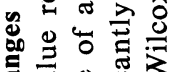

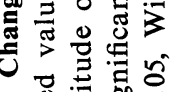

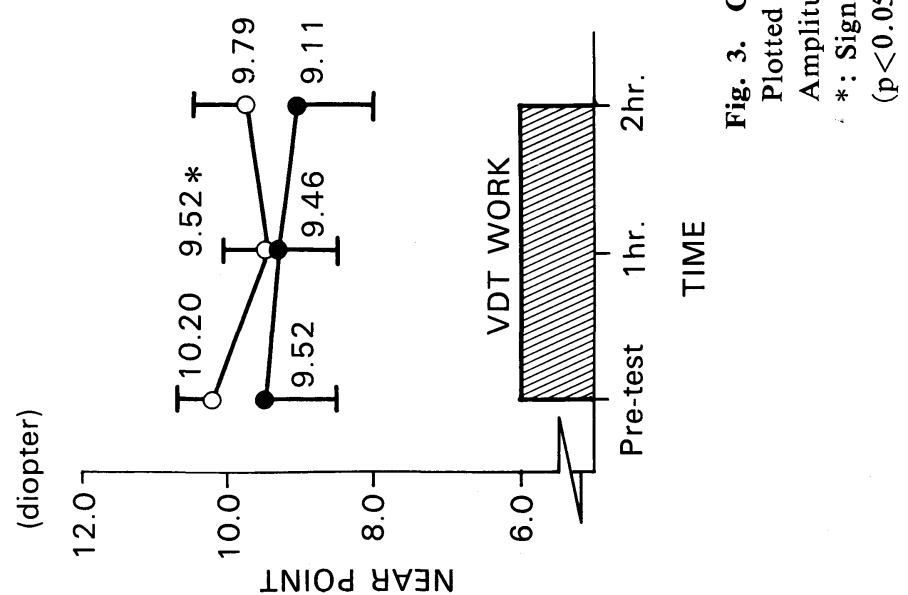


0.78 after one hour, and 0.77 at two hours, reflecting a decrease as VDT work time progressed. Visual acuity was significantly lower following one hour's VDT work, compared to the pre-test level $(\mathrm{P}<0.05$, Wilcoxon matched-pairs signed-rank test). ${ }^{21)}$ In the non-dominant eye, visual acuity tended to decrease, but not significantly.

Figure 3 gives the variation in accommodative function. The mean near point distance was $10.2 \mathrm{D}$ in the dominant eye at pre-work testing, against a mean far point distance of $0.63 \mathrm{D}$. The mean difference in accommodation capacity was $9.57 \mathrm{D}$.

The mean near point distance was 9.52 D after 1 hour of VDT work, and a significant elongation of distance was noted $(\mathrm{P}<0.05)$. The mean far point distance was $0.83 \mathrm{D}$ after 2 hours of VDT work, reflecting a significant reduction in distance $(\mathrm{P}<0.05)$. Mean amplitude of accommodation was $8.76 \mathrm{D}$ after an hour of work, and $8.96 \mathrm{D}$ at two hours. Both showed a significant decrease $(P<0.05)$. The non-dominant eye presented no significant difference with any function of accommodation. In this way, the dominant eye evidenced a marked influence due to the VDT work, so fluctuating accommodation was similarly investigated in the dominant eye.

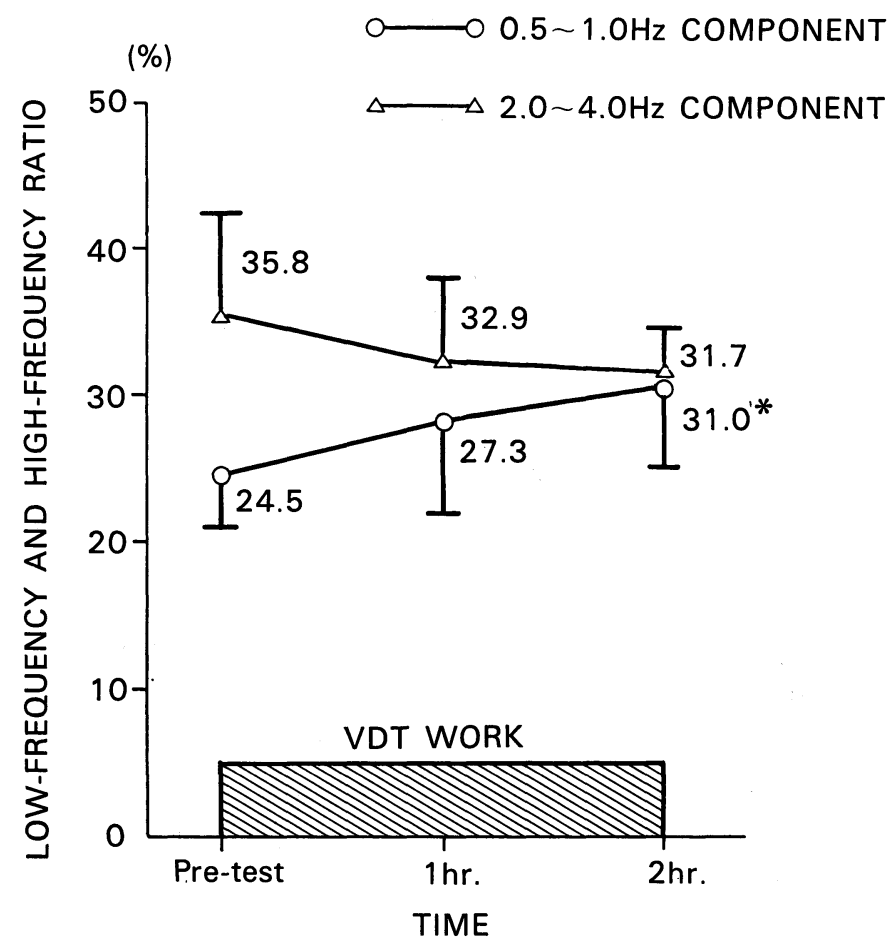

Fig. 4. Changes in fluctuating accommodation with VDT work.

Plotted value represents means \pm S.D. for eight subjects.

*: Significantly different from the pre-test level.

$(\mathrm{p}<0.05$, Wilcoxon matched-pairs signed-rank test) 


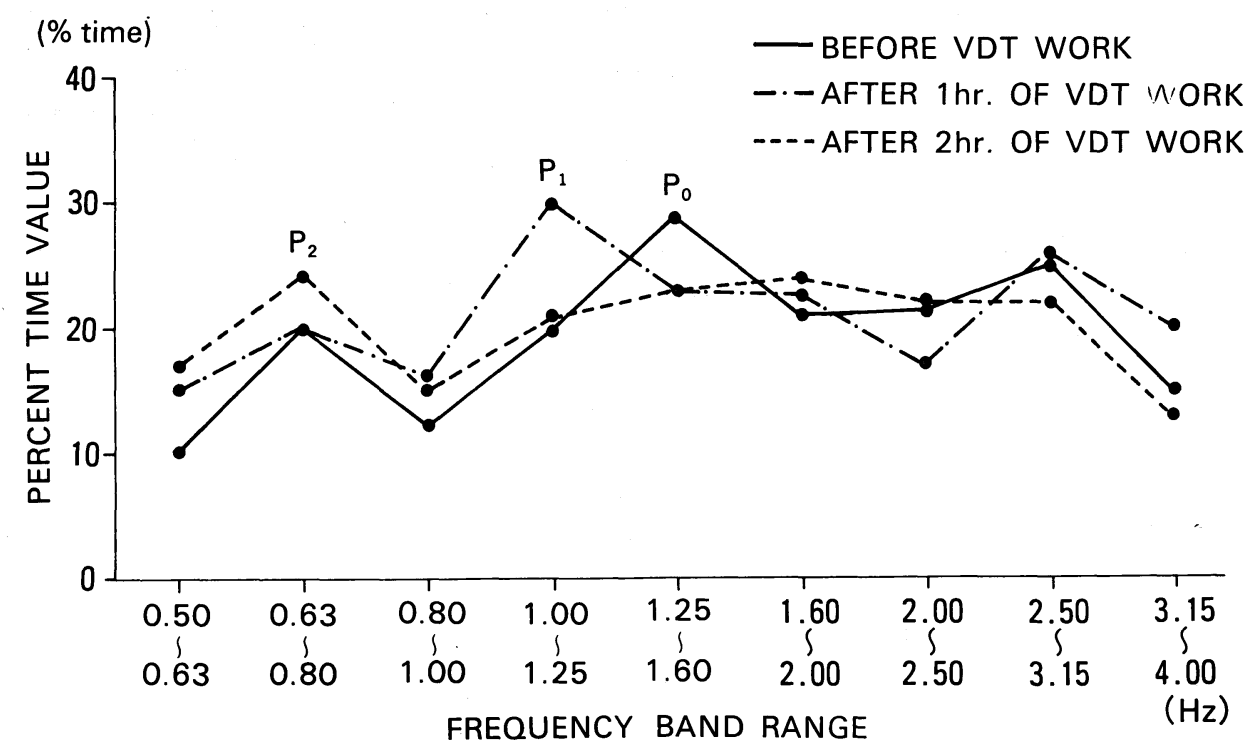

Fig. 5. Mean frequency spectrum distribution of the percent time value. Plotted value represents means for eight subjects.

$P_{0}$ : Peak frequency band before VDT work

$P_{1}$ : Peak frequency band after $1 \mathrm{hr}$. of VDT work

$\mathrm{P}_{2}$ : Peak frequency band after $2 \mathrm{hr}$. of VDT work

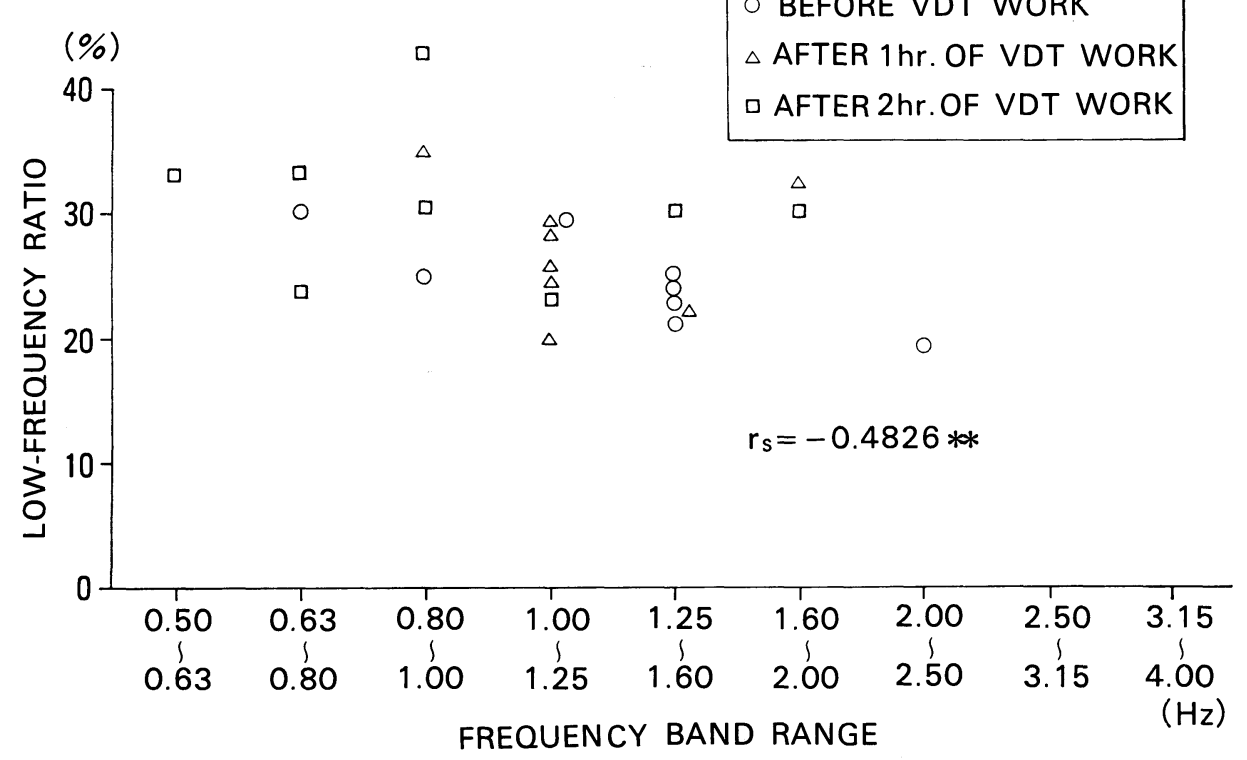

Fig. 6. Relationship between low-frequency ratio and peak frequency band range. Plotted value shows the individual data.

$\mathrm{r}_{\mathrm{s}}$ : Spearman's correlation coefficient $(* *: \mathrm{p}<0.01)$ 


\section{1-3. Fluctuations in accommodation}

The mean low-frequency ratio of fluctuations in accommodation was presented in Fig. 4. The ratio was 24.5 percent at pre-testing, 27.3 percent after an hour's work, and 31.0 percent at the two-hour work. There was a significant increase over the pre-test level in fluctuating accommodation at the 2-hour point in the VDT work $(\mathrm{P}<0.05)$.

Figure 5 gives the mean frequency spectrum distribution of the percent time value. The peak frequency band range before testing was $1.25-1.60 \mathrm{~Hz}$, against $1.00-1.25 \mathrm{~Hz}$ after an hour's work and $0.63-0.80 \mathrm{~Hz}$ following two hours' work with VDT. The peak frequency band range thus tended to become lower.

In Fig. 6 are seen the individual subject differences in the relationship between the low-frequency ratio and the peak frequency band range. A negative correlation was found between the peak frequency band range and the low-frequency ratio. 1-4. Mean number of subjective complaints

The mean number of complaints regarding eye strain and subjective symptoms was computed as indicated in Table 2 . There were virtually no subjective complaints voiced before VDT work began. After an hour's work, complaints of eye strain averaged about 2.50 in number, while at two hours they came to 4.75. As to subjective fatigue, complaints numbered 3.50 after an hour of VDT effort, against 7.38 at two hours. Symptoms of eye strain and subjective fatigue both increased on average with the course of VDT working time, in terms of the type of complaints made by subjects. Subjective complaints also increased significantly at 1 and 2 hours into the work, compared to the pre-test levels, in terms of the mean number of different complaints registered $(P<0.05)$. Also, with the 30 subjective fatigue types of complaints as well as the 10 difficulties in

Table 2. The average number of subjective complaints

\begin{tabular}{|c|c|c|c|}
\hline & $\begin{array}{l}\text { Before } \\
\text { VDT work }\end{array}$ & $\begin{array}{l}\text { After } 1 \mathrm{hr} \\
\text { VDT work }\end{array}$ & $\begin{array}{l}\text { After } 2 \mathrm{hr} \\
\text { VDT work }\end{array}$ \\
\hline $\begin{array}{l}\text { Eye strain } \\
(23 \text { items })\end{array}$ & 0.13 & 2.50 & 4.75 \\
\hline $\begin{array}{l}\text { Fatigue complaints } \\
\quad(30 \text { items })\end{array}$ & 0.00 & $\begin{array}{c}3.50 \\
-11 \\
-*\end{array}$ & $i^{7.38}$ \\
\hline $\begin{array}{l}\text { Dullness and sleepiness } \\
\quad(10 \text { items })\end{array}$ & 0.00 & 2.13 & 3.88 \\
\hline $\begin{array}{l}\text { Difficulty of concentration } \\
\quad(10 \text { items })\end{array}$ & 0.00 & 0.63 & 2.25 \\
\hline $\begin{array}{l}\text { Sense of something physically wrong } \\
\text { (10 items) }\end{array}$ & 0.00 & 0.75 & 1.25 \\
\hline
\end{tabular}

The average value of complaints was calcutated by the formula.

$$
\mathbf{M}=\frac{\text { Gross number of complaints in a group }}{\text { Number of subjects }}
$$

* $\mathrm{p}<0.05$, Wilcoxon matched-pairs signed-rank test. 


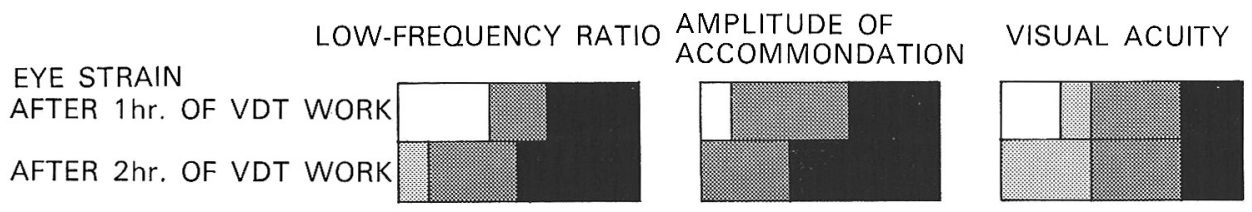

FATIGUE COMPLAINTS
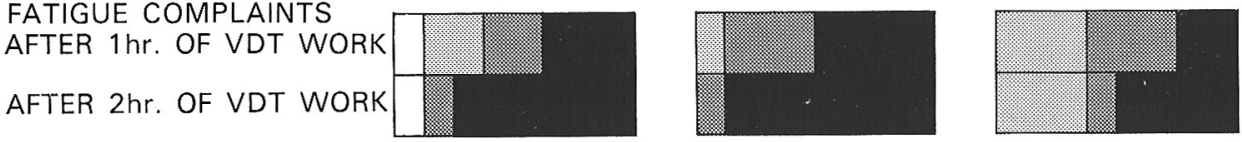

EIGHT SUBJECTS

Fig. 7. Relationship between visual function (low frequency ratio, amplitude of accommodation and visual acuity) and subjective symptoms (eye strain and fatigue complaints)

(unit: number of subjects)

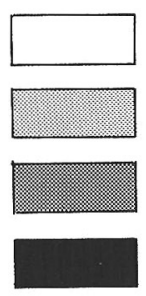

Number of complaints is 2 or less and visual function is no worse than the pre-test level.

Number of complaints is 3 or more and visual function is no worse than the pre-test level.

Number of complaints is 2 or less and visual function is worse than the pre-test level.

Number of complaints is 3 or more and visual function is worse than the pre-test level.

concentration, the spread in complaints in terms of category increased significantly by the second hour of VDT work as opposed to the first hour $(\mathrm{P}<0.05)$.

2. Relationship between visual function and number of subjective complaints

A small number of complaints in terms of symptom type was considered to be 2 or less, while 3 or more was taken to be frequent complaints of subjective type. With the low-frequency ratio, a level more than the pre-test value was considered to be a diminishment in fluctuating accommodation. With amplitude of accommodation, a level less than the pre-test value was taken to be a diminishment in the accommodative function. With visual acuity, a level less than the pre-test value was considered to be a diminishment. Figure 7 was drawn with these criteria as the basis.

Generally speaking, the number of people with numerous subjective complaints and diminished visual functions increased more after two hours of VDT work than after one hour of same. The low frequency ratio for fluctuations in accommodation increased in 5 persons at the end of the first hour and in 7 persons at the end of the second hour, whereas accommodative amplitude decreased; 7 persons displayed its lessening at the end of the first hour, but all subjects 
showed it after 2 hours of VDT work. In case of the subjects who had less than 2 eye-related subjective complaints, the low frequency ratio of fluctuating accommodation and accommodative amplitude changed for the worse.

The decrease in visual acuity remained at the same level either after 1 or 2 hours of VDT work, but the number of subjects with many complaints increased.

\section{Discussion}

A relatively high proportion of VDT operators in Japan is young women, and they correspond to the subjects (18 years of age) in this experiment. The present subjects had no VDT operational experience and underwent a brief practice on the system the day before the actual 2-hour search task was conducted. This brief training and actual VDT work correspond to the frequent experience of young female employees in an office situation. In this case, their visual load and mental stress are great, presumably because of their inexperience as VDT operators.

As indicated by the trend in the information transmission ratio, the accuracy tended to improve in the last half as opposed to the first half of the VDT work hour. This was regarded as the effect of training and reflects the high morale of the volunteers.

The search task in the present experiment was characterized by the fact that subjects had to focus on the CRT display continuously, could not adjust the working speed, were required to judge accurately, to act immediately, to maintain a fixed posture, and to show more sophisticated recognition for characters than needed for alphanumerics. Therefore, it is safe to consider that the character search task entails great visual demands. ${ }^{22)}$ The visual distance from subject to screen was $40-60 \mathrm{~cm}$, the normal distance in actual VDT work in Japan. ${ }^{23)}$

A difference in the level of visual function was noted from eye to eye (leftright). In this study, visual acuity and accommodative function were considered separately for the dominant eye and the non-dominant one. Visual acuity in the dominant eye significantly diminished in relation to the pre-test level after an hour's VDT operation, and the near point distance was also significantly extended. After 2 hours' operation, the far point of the dominant eye was significantly shortened. The non-dominant eye tended to show reduced visual acuity and accommodative function, but the difference did not prove to be significant.

Among existing studies in the literature dealing with visual load from VDT work, Oestberg ${ }^{24}$ used laser optometry in an experiment, in which he reported a temporary decrease in accommodative function due to VDT work. Kurimoto et al. ${ }^{25)}$ employed an accommodo polyrecorder in their experiment to find that VDT work lengthened near point distance and prolonged the accommodative construction time. Krueger ${ }^{26)}$ reported that VDT tasks resulted in lessening of 
visual acuity in myopic subjects, while Suzumura et $a l .{ }^{27)}$ indicated a diminishment in dynamic acuity. The present results, on the other hand, corroborated these findings.

In the present investigation, it was clear that accommodative function of the dominant eye was affected by focusing on the CRT display screen. The focusing on the CRT display was suggested to cause a possibly increased visual load due to the dominant eye. In this connection, Friedlander ${ }^{28)}$ reported that visual acuity was greater in the dominant of the two eyes. But no report to date has dealt with possible effects on the dominant eye by visual activity such as VDT work. In the study here, albeit the subjects were few in number, a distinction presumably must be made between the dominant and non-dominant eye in order to determine the influence of VDT work.

Even when focusing on a single point, the eye constantly changes the curve of its crystalline lens in order to perform accommodation. Campbell et al. ${ }^{12)}$ called this the fluctuations of accommodation. He noted that "When the retina ceases to obtain information on focus position, the lower frequency components are increased. It is concluded that sensory feedback must play a role." Suzumura ${ }^{29)}$ developed an infrared optometer to measure "floating" accommodation.

In the present study, using an infrared optometer, the subjects were made to focus at a point $1 \mathrm{D}$ toward them from the far point, and the scale method of Miyao et al. ${ }^{14)}$ was used for computer analysis. Usually, in the measurement of visual functions, the subjective judgment of the subject is frequently called into play. But with an infrared optometer, measurement is possible without this subjective aspect. Computer analysis with the scale method offers better repeatability and objectivity than the conventional observational approach to analysis.

From the results of the experiment, the peak frequency band range was 1.25$1.60 \mathrm{~Hz}$ before the VDT work, $1.00-1.25 \mathrm{~Hz}$ after the first hour, and 0.63-0.80 $\mathrm{Hz}$ after the second hour, evidencing a lower frequency spectrum. The lowfrequency ratio, on the other hand, was 24.5 percent before the VDT task, 27.3 percent after one hour, and 31.0 percent after two hours of the work. The level was significantly greater at 2 hours compared to the pre-test level.

Kurimoto et al. ${ }^{25}$ ) used an infrared optometer in a VDT work experiment revealing that the low-frequency ratio was augmented. In the present investigation, using the scale method with computer analysis of fluctuating accommodation, the same findings as to the effects of VDT work were obtained as in the above study. Takeda et al. ${ }^{30)}$ measured the accommodation area by dynamic refractometer, and reported a decrease in accommodative function due to VDT work.

It was evident that as subjects became more involved in their work, performance increased, while subjective complaints were on the rise. It is well known that VDT work causes a higher percentage of eye strain complaints and fatigue symptoms than non-VDT work. From their field testing, Miyao et al. ${ }^{31)}$ found a close relationship between the eye strain complaint percentage and the length 
of VDT usage. In the present investigation, this was experimentally corroborated. Also, there was a significant increase in the various complaints related to the difficulty of concentration voiced in the second hour of work as opposed to the first hour. The accuracy of the work accomplished in the VDT search task improved, thanks to the training in character work and the high morale, but the findings suggest that the nervous tension accompanying VDT work is considerable.

Few reports in the literature have dealt with the connection between visual function and subjective complaints. From his field study, Groot ${ }^{32)}$ found that, in groups with many complaints, visual acuity was low, and the near point distance was prolonged. Generally speaking, in the present study, the frequent subject complaints-diminished visual function relationship was stronger in the second hour of VDT work as opposed to the first hour.

The increase in the low frequency ratio of fluctuating accommodatoin and decrease in accommodative amplitude preceded the increase in subjective complaints; and the increase in these subjective complaints preceded the decrease in visual acuity. Subjective complaints reportedly tend to emerge earlier in VDT work than in other types of work. In the present study, the low frequency ratio increase and accommodative amplitude decrease emerged before the subjective complaints. Worker health measures must be arranged so that such effects do not take their cumulative fatigue. The present experimental results made it clear that the effects of VDT work in unskilled subjects can be identified when the task is seriously undertaken, and that computer analysis using the scale method offers an early and objective approach to measure visual load.

\section{ACKNOWLEDgements}

The authors wish to express their appreciation to Drs. H. Kuno and H. Iguchi, Toyota Central Res. \& Develop. Labs., for their incisive advice. We also wish to thank Prof. H. Ichikawa for his encouragement and Dr. S. Yamamoto, National Institute of Industrial Health, for his helpful suggestions.

\section{REFERENCES}

1) Grandjean, E. (1980). Ergonomics of VDUs: Review of present knowledge (Grandjean, E. and Vigliani, E. ed., Ergonomic aspects of visual display terminals) p. 1, Taylor \& Francis, London.

2) Maeda, K., Horiguchi, S. and Hosokawa, M. (1982). History of the studies on occupational cervicobrachial disorder in Japan and remaining problems, J. Human Ergology, 11, 17.

3) Laubli, T., Hunting, W. and Grandjean, E. (1981). Postural and visual loads of VDT workplaces. 2. Lighting conditions and visual impairments, Ergonomics, 24, 933.

4) Nishiyama, K., Nakaseko, M. and Uehata, T. (1984). Health aspects of VDT operators in the newspaper industry (Grandjean, E. ed., Ergonomics and health in modern 
offices) p. 113, Taylor \& Francis, London.

5) Hunting, W., Laubli, T. and Grandjean, E. (1981). Postural and visual loads at VDT workplaces. 1. Constrained postures, Ergonomics, 24, 917.

6) Onishi, N., Sakai, K. and Kogi, K. (1982). Arm and shoulder muscle load in various keyboard operating jobs of women, J. Human Ergology, 11, 89.

7) Smith, M. J., Cohen, B. F. and Stammerjohn, L. W. (1981). An investigation of health complaints and job stress in video display operations, Human Factors, 23, 387.

8) Slesin, L. and Zybko, M. (1983). Video display terminals: health and safety experts from microwave news, Philips Holzer \& Associates, New York.

9) Nilsen, A .(1982). Facial rash in visual display unit operators, Contact Dermatitis, 8, 25 .

10) Dainoff, M. J. (1980). Visual fatigue in VDT operators, (Grandjean, E. and Vigliani, E. ed., Ergonimic aspects of visual display terminals) p. 95, Taylor \& Francis, London.

11) Rey, P. and Meyer, J. J. (1980). Visual impairments and their objective correlates, (Grandjean, E. and Vigliani, E. ed., Ergonomic aspects of visual display terminals) p. 77, Taylor \& Francis, London.

12) Campbell, F. W., Robson, J. G. and Westheimer, G. (1959). Fluctuations of accommodation under steady viewing conditions, J. Physiology, 145, 579.

13) Campbell, F. W. and Robson, J. G. (1959). High-speed infrared optometer, J. Opt. Soc. Am., 49, 268.

14) Miyao, M., Tanahashi, M., Akamatsu, Y., Tomiyasu, S., Kuno, H. and Iguchi, H. (1986). Infrared optometer in assessment of visual fatigue: Computer analysis of the scale method, international scientific conference: Work with display units (Proceedings part 2), p. 859.

15) Japanese Ministry of Labor, (1985). Technical evolution and workers conditions, p. 138, Japan (In Japanese).

16) Suzumura, A. (1981). Eye strain ,Ophthalmology, 23, 799 (In Japanese).

17) Yoshitake, H. (1971). Relations between the symptoms and the feeling of fatigue, Ergonomics, 14, 175.

18) Iwasaki, T., Kurimoto, S., Sagara, K., Noro, K., Yamamoto, S. and Yoshioka, M. (1982). The influence of VDT work on accommodation, Folia Ophthalmologica Japonica, 33, 90 (In Japanese).

19) Shannon, C. E. and Weaver, W .(1949). The mathematical theory of communication, Univ. of Illinois Press, Champaign, Illinois.

20) Coren, S. and Kaplan, C. P. (1973). Patterns of ocular dominance, American J. of Optometry and Physiological Optics, 50, 283.

21) Wilcoxon, F. (1947). Probability tables for individual comparisons by ranking methods, Biometrics, 3, 119.

22) National Institute for Occupational Safety and Health (1981). NIOSH research report: Potential health hazards of video display terminals, Public Health Service, Cincinnati, Ohio.

23) Japanese Ministry of Labor, (1985). Guidelines to occupational health in VDT operation, Ministry of Labor, Tokyo (In Japanese).

24) Oestberg, O. (1980). Accommodation and visual fatigue in display work, (Grandjean, E. and Vigliani, E. ed., Ergonomic aspects of visual display terminals) p. 41, Taylor \& Francis, London.

25) Kurimoto, S., Iwasaki, T., Nomura, T., Noro, K. and Yamamoto, S. (1983). Influence of VDT work on eye accommodations, J. UOEH, 5, 101.

26) Krueger, H. (1980). Ophthalmological aspects of work with display workstations, (Grandjean, E. and Vigliani, E. ed., Ergonomic aspects of visual display terminals) p. 31, Taylor \& Francis, London. 
27) Suzumura, A., Atsumi, K., Mizutani, S. and Tsujimura, H. (1984). Image filter investigation to counter asthenopic characteristic due to VDT operation, Nihon Ganko Gakkaishi, 5, 28 (In Japanese).

28) Friedlander, W. J. (1981). Some aspects of eyedness, Cortex, 7, 357.

29) Suzumura, A. (1975). Research on fluctuation of accommodation, Act. Soc. Ophthalmol. Jpn., 79, 1257 (In Japanese).

30) Takeda, T., Fukui, Y., Iida, T. and Karasuyama, K. (1985). An objective measurement apparatus for accommodation ability change caused by VDT work, Nihon Ganko Gakkaishi, 6, 59.

31) Miyao, M., Sakakibara, H., Tanahashi, M., Muramatsu, T., Yamauchi, T., Kondo, A., Takihi, K., Ono, Y., Toda, Y. and Maeda, K. (1985). Visual loads of workers operating visual display terminals, J. Nagoya Med. Assoc., 108, 27 (In Japanese).

32) Groot, J. P. (1983). Eyestrain in VDU users: Physical correlates and long-term effects, Human Factors, 25, 409. 